\title{
Synergy Between a Shallow Root System With a DRO1 Homologue and Localized P Application Improves Rice P Uptake
}

\author{
Aung Zaw Oo \\ Japan International Research Center for Agricultural Sciences \\ YASUHIRO TSUJIMOTO ( $\nabla$ tsjmt@affrc.go.jp ) \\ Japan International Research Center for Agricultural Sciences \\ Mana Mukai \\ Japan International Research Center for Agricultural Sciences \\ Tomohiro Nishigaki \\ Japan International Research Center for Agricultural Sciences \\ Toshiyuki Takai \\ Japan International Research Center for Agricultural Sciences \\ Yusaku Uga \\ Institute of Crop Science, National Agriculture and Food Research Organization
}

\section{Research Article}

Keywords: Improved phosphorus (P), Root system architecture (RSA), Near-isogenic lines (NILs)

Posted Date: January 5th, 2021

DOI: https://doi.org/10.21203/rs.3.rs-138072/v1

License: () (1) This work is licensed under a Creative Commons Attribution 4.0 International License. Read Full License 


\section{Abstract}

Improved phosphorus $(\mathrm{P})$ use efficiency for crop production is needed given the depleting phosphorus ore deposits and increasing ecological concerns about its excessive use. Root system architecture (RSA) is important in efficiently capturing immobile $\mathrm{P}$ in soils, while agronomically, localized $\mathrm{P}$ application near the roots is a potential approach to address this issue. However, the interaction between genetic traits of RSA and localized P application has been little understood. Near-isogenic lines (NILs) and their parent of rice (qsor1-NIL, Dro1-NIL, and IR64, with shallow, deep, and intermediate root growth angles (RGA), respectively) were grown in flooded pots after placing $\mathrm{P}$ near the roots at transplanting (P-dipping). The experiment identified that the P-dipping created an available $\mathrm{P}$ hotspot at the soil surface; the qsort-NIL had the greatest root biomass and root surface area in the $0-3 \mathrm{~cm}$ soil layer despite no genotype differences in total values; the qsor1-NIL had significantly greater biomass and P uptake than the other genotypes in the P-dipping. The superior surface root development of qsor7-NIL could have facilitated P uptakes from the $\mathrm{P}$ hotspot, implying that $\mathrm{P}$-use efficiency in crop production can be further increased by combining genetic traits of RSA and localized P application.

\section{Introduction}

Phosphorous deficiency restricts crop growth, particularly in the tropics, due to the inherently low $\mathrm{P}$ content of soils and the high P-fixing capacity of other minerals such as active Al-and Fe- oxides ${ }^{1}$. Large amounts of mineral P fertilizer have been continuously applied to overcome low P-use efficiency and achieve high grain yields. Given the finite nature of the $P$ fertilizer resource and increasing ecological concerns about the excess use of $P$ in agricultural systems ${ }^{2,3,4}$, it is vital to investigate sustainable crop production strategies that facilitate the efficient utilization of applied and available $\mathrm{P}$ in soils. Such strategies are also critical for the food security of resource-poor farmers with low fertilizer inputs in developing countries ${ }^{5}$.

Roots play a pivotal role in exploring immobile $\mathrm{P}$ in the soil. An increased root surface area with minimal carbon costs is one strategy, through the formation of finer roots, aerenchyma, and root hairs $6,7,8$. Changes in root system architecture (RSA) such as the development of surface roots is another root function to adapt to $\mathrm{P}$ deficiency, that is so called topsoil foraging, because $\mathrm{P}$ is most available in surface soil layers ${ }^{9}$. This topsoil foraging can be enhanced by a shallower growth angle of axial roots ${ }^{9}$, adventitious root abundance ${ }^{10}$, and many/short lateral root branching ${ }^{11}$. Field-based studies have demonstrated the yield advantages of genotypes with these architectural traits for several crops under Pdeficiency ${ }^{8}$. Therefore, identification of key root traits and their genetic mechanisms and conferring genes or quantitative trait loci (QTL) should offer avenues for improving P acquisition efficiency in crop breeding $^{12}$.

Agronomic approach for improving P-use efficiency includes localized fertilization, which refers to the placement of small amounts of fertilizers nearby the root zone. Several field experiments have 
demonstrated the positive impacts of localized $P$ fertilization on grain yields and/or fertilizer use efficiencies for crop production (e.g., Vandamme et al. ${ }^{13}$ ). Our recent study identified that applied P-use efficiency can be substantially improved by dipping seedling roots in P-enriched slurry at transplanting (Pdipping) in severely P-deficient rice fields in Madagascar ${ }^{14}$. The P-dipping transfers $\mathrm{P}$, with the slurry attached to seedling roots, creating a soluble $P$ hotspot nearby the transplanted roots and facilitating plant $\mathrm{P}$ uptake, even under the high P-fixing soils of the tropics ${ }^{15}$. The use of P-dipping is currently being tested by hundreds of smallholder farmers in Madagascar.

Despite a range of studies in both genetic and agronomic approaches, none have examined how the combination of RSA traits and localized fertilization would affect plant P-use and acquisition efficiencies. In the present study, we aimed to identify the combination effect by using near-isogenic lines (NILs) of DRO1 and its homologue ( $q S O R 1$ ), the major QTLs of rice controlling root growth angle (RGA). The parent variety, IR64, is a high-yielding, modern variety with a relatively shallow RGA with the combination of the nonfunctional allele of DRO1 and the functional allele of qSOR1. The Dro1-NIL, developed by Uga et al. ${ }^{16}$, has a relatively deep RGA with the combination of functional alleles of both DRO1 and qSOR1. The qsor1NIL, developed by Kitomi et al. ${ }^{17}$, has a shallower RGA than IR64, with the combination of nonfunctional alleles of both DRO1 and $q S O R 1$. We hypothesize that P-dipping, creating the $\mathrm{P}$ hotspot at the soil surface, will have a positive interaction with the shallow root system in rice. By understanding the interaction, further research can be expected to improve applied P use efficiencies by designing RSA traits for localized fertilizer application techniques.

\section{Results}

\section{Shoot growth and $\mathrm{P}$ uptake}

Localized $\mathrm{P}$ application via $\mathrm{P}$-dipping $\left(\mathrm{P}_{\text {dip }}\right)$ achieved equivalent biomass and $\mathrm{P}$ uptakes at one fifth of the application rate of uniform $P$ incorporation $\left(P_{\text {inco }}\right)$ (Fig. 1). The ANOVA detected consistent and significant interactions between genotype and $\mathrm{P}$ treatment for shoot biomass and $\mathrm{P}$ uptakes at both 21

days after transplanting (DAT) and 42 DAT. In the $\mathrm{P}_{\text {dip }}$ treatment, qsor1-NIL consistently had greater shoot biomass and $\mathrm{P}$ uptake than Dro1-NIL. In contrast, in $\mathrm{P}_{\text {inco, }}$ Dro 1-NIL tended to have greater shoot biomass and significantly greater $P$ uptakes than the other genotypes at 42 DAT. Applied P-use efficiency (calculated as the ratio of shoot $\mathrm{P}$ uptake at 42 DAT to the amount of $\mathrm{P}$ applied) increased from $3.4 \%$ to $16.2 \%$ for IR64 by changing the $\mathrm{P}$ application methods from $\mathrm{P}$ incorporation to P-dipping and further increased to $20.0 \%$ by using qsor1-NIL (data not shown).

\section{Genetic root traits}

The RSA traits among genotypes were consistent under $\mathrm{P}_{\text {dip }}$ : the RGA was the shallowest in the order of qsor1-NIL > IR64 > Dro1-NIL at both 21 DAT and 42 DAT (Fig. 2). As a result of the RGA differences, qsor1NIL developed a large proportion of root biomass and root surface area in the $0-3 \mathrm{~cm}$ layer and little in the 14-28 cm layer. In contrast, Dro1-NIL distributed a relatively large proportion of root mass in the 14- 
$28 \mathrm{~cm}$ layer. For instance, at 21 DAT, qsor7-NIL developed $50.3 \%$ of the root mass in the $0-3 \mathrm{~cm}$ layer and only $2.0 \%$ in the $14-28 \mathrm{~cm}$ layer while these proportions were $32.7 \%$ and $10.3 \%$ for Dro $1-\mathrm{NIL}$. The root distribution pattern of IR64 was intermediate between qsor7-NIL and Dro 1-NIL. The trend in RSA among genotypes were the same in $\mathrm{P}_{\text {inco }}$ while IR64 and Dro 1-NIL tended to have deeper RGAs than those in $\mathrm{P}_{\text {dip }}$ (Fig. 3). The RGAs of qsor1-NIL, IR64, and Dro1-NIL at 21 DAT were $7.1^{\circ}, 23.6^{\circ}$, and $33.3^{\circ}$ in $\mathrm{P}_{\text {dip }}$ and $5.0^{\circ}$, $39.8^{\circ}$, and $52.2^{\circ}$ in $\mathrm{P}_{\text {inco. }}$.

By reflecting the differences in RSA, Dro1-NIL had a greater root biomass, greater root surface areas, and longer lateral and nodal root length than the other genotypes in the 14-28 cm layer (the difference was only significant vs. qsor1-NIL), despite its significantly lower values in the total for these parameters at 21 DAT (Fig. 4). At 42 DAT, there were no significant differences in the total values of these parameters except nodal root length, whereas genotype root distribution patterns were retained within each soil layer: the qsor1-NIL had significantly greater root mass, greater root surface area, and longer nodal root length than Dro1-NIL in the $0-3 \mathrm{~cm}$ layer and vice versa in 14-28 cm (Fig. 4). IR64 was intermediate for these parameters in both the $0-3 \mathrm{~cm}$ and $14-28 \mathrm{~cm}$ layers.

\section{Spatio-temporal dynamics in soluble P concentrations}

Soluble P concentrations in soils were averaged across genotypes because there were no significant genotype differences in any sampling times or sampling layers. The $\mathrm{P}_{\text {dip }}$ had a substantially large soluble $P$ concentration at a depth of $3 \mathrm{~cm}$ (Fig. 5). The maximum $P$ concentration at a depth of $3 \mathrm{~cm}$ for $P_{\text {dip }}$ was $>100$ times greater than the other depths for both $P$ treatments throughout the growing period. In $P_{\text {dip }}$, soluble $P$ concentrations were greater at a depth of $7 \mathrm{~cm}$ than at $21 \mathrm{~cm}$ in the latter growth stages, but apparently the vertical $P$ diffusion from the $3 \mathrm{~cm}$ hotspot was relatively small. In contrast, the soluble $\mathrm{P}$ concentrations were significantly higher at a depth of $21 \mathrm{~cm}$ than at $7 \mathrm{~cm}$ in $\mathrm{P}_{\text {inco }}$ after 28 DAT.

\section{Discussion}

The results support the hypothesis that the shallow root system of qsor1-NIL has a positive interaction with localized $\mathrm{P}$ application via P-dipping and that the combination additively improves applied P-use efficiency for initial rice growth. The other genotypes also reduced the RGA by $16-19^{\circ}$ in response to the P hotspot (Fig. 2, 3), yet the synergy with P-dipping was greater in qsor1-NIL. This implies that breeding efforts to design the RGA in localized $P$ spots can be more beneficial than relying on the intrinsic root plasticity of each genotype.

Superior P uptake of qsor7-NIL with P-dipping is attributable to the greater root biomass and root surface area in the $0-3 \mathrm{~cm}$ soil layer where high soluble $\mathrm{P}$ is available throughout the growing period. This is most likely the same mechanism as topsoil foraging, prioritizing the root development in the P-rich domains to efficiently capture immobile $P$ in soils. Spatio-temporal $P$ variations in the P-dipping indicate that applied $\mathrm{P}$ mobility is highly restricted despite a general understanding that $\mathrm{P}$ becomes less immobile under flooded conditions ${ }^{18}$, emphasizing the importance of RSA for the localized P acquisition, even 
under flooded soil culture. The relative immobility of applied P even in irrigated lowlands was also reported by Akahane et al. ${ }^{19}$, in which they detected high amount of $\mathrm{P}$ retained up to harvest within a small area of $2 \mathrm{~cm}$ (vertical) by $4 \mathrm{~cm}$ (horizontal) from the application spot.

The effect of topsoil foraging itself has been reported in several upland crops $11,20,21,22$, but not in rice. Previous studies detected no significant effects of root distribution patterns or RGA for rice P acquisition under $\mathrm{P}$ deficiency (e.g., Mori et al. ${ }^{23}$ ), which may be due to the materials differing not only in root system architecture but in other traits or in more complex screening environments. The present study had an advantage using NILs differing in RGAs otherwise equivalent phenotypes ${ }^{17}$ under non-water-stressed and greatly uneven $\mathrm{P}$ availability by P-dipping.

In addition, the present study detected a positive effect of Dro1-NIL for P uptake under uniform, Psufficient conditions. The reason for this positive interaction should be further explored but can be related to consistent $\mathrm{P}$ acquisition from the $\mathrm{P}$-rich subsoil layers after the depletion of available $\mathrm{P}$ in topsoil layers (Fig. 5). Another potential reason is the more efficient acquisition of other nutrients, such as N, which is vertically more mobile than $\mathrm{P}$. Deep rooting has been reported as a positive trait for $\mathrm{N}$ acquisition of upland crops $^{8}$ and also of rice in flooded paddy fields in the latter growth stages ${ }^{24}$. In common bean, Rangarajan et al. postulated that the greater vertical range of roots with deeper RGA and greater number of basal root whorls is advantageous for biomass production when both $\mathrm{N}$ and $\mathrm{P}$ are deficient ${ }^{25}$. Likewise, dispersed root distribution of Dro1-NIL might have benefited from relatively uniform nutrient conditions of the $\mathrm{P}_{\text {inco }}$ treatment. Dro1-NIL had significantly smaller coefficient of variations across soil layers in root biomass at 42 DAT than qSOR1 (23\% vs. $47 \%$ ), indicating more uniform and dispersed root development.

It should be noted that crop production environments are complex with multiple abiotic stresses, particularly on smallholder farms in developing countries where stress-resilient and nutrient-efficient technologies are most needed. With this respect, field-based experiments to maturity are further required to confirm the combination effect between genetic RSA traits and P fertilizer management practices. The combination of shallow roots and localized $P$ application can never be a silver bullet. A careful selection of field environments where $P$ deficiency is the primary limiting factor is needed to effectively apply this combination, ideally together with the development of bimodal root phenotypes (shallow and deep) or

high RSA plasticity ${ }^{26}$ against complex growing environments. In rice, qSOR1 and DRO1 can be promising genetic resources for the development of such bimodal root phenotypes, as indicated by previous studies $^{27,28}$.

\section{Conclusion}

The study provides a significant evidence by using NILs differing in their RGA that a shallow root system has a positive interaction with localized $P$ application nearby the root at transplanting, and the combination substantially improves applied-P use efficiency for initial rice growth. This finding should 
encourage relevant research focusing not only on physiological root traits or agronomic management approaches, but on their combination to address to the global issue of increasing crop production while minimizing the environmental impacts.

\section{Materials And Methods}

\section{Experimental design and treatments}

The experiment was conducted in a greenhouse with an automatic ventilation system at the Japan International Research Center for Agricultural Science (JIRCAS), Tsukuba, Japan. The average daytime and nighttime temperatures during the experiment ranged from $26.2^{\circ}$ to $35.8^{\circ} \mathrm{C}$ and $24.7^{\circ}$ to $28.7^{\circ} \mathrm{C}$, respectively (Thermo Recorder TR-50U2, T\&D Corporation, Japan).

The soil for the experiment was collected from a subsoil layer (40-50 cm in depth) at the JIRCAS Tropical Agricultural Research Front, Okinawa, Japan. Physicochemical properties of experimental soil are summarized in Table 1 . The soil was silty clay with a $\mathrm{pH}\left(\mathrm{H}_{2} \mathrm{O}\right)$ of 4.86 and low available $\mathrm{P}$ content, and high $\mathrm{P}$ retention capacity with abundant active $\mathrm{Al}$ and Fe oxides. The soil was air-dried and passed through an $8 \mathrm{~mm}$ sieve prior to the experiment.

\section{Table 1 Physicochemical properties of soil}




\begin{tabular}{|ll|}
\hline Parameters & Red-yellow soil \\
\hline $\mathrm{pH}\left(\mathrm{H}_{2} \mathrm{O}\right)$ & 4.86 \\
\hline $\mathrm{EC}\left(\mathrm{mSm}^{-1}\right)$ & 4.63 \\
\hline Total $\mathrm{N}\left(\mathrm{g} \mathrm{kg}^{-1}\right)^{\mathrm{a}}$ & 0.91 \\
\hline Total C $\left(\mathrm{g} \mathrm{kg}^{-1}\right)^{\mathrm{a}}$ & 4.82 \\
\hline $\mathrm{P}$ retention $(\%)^{\mathrm{b}}$ & 57.5 \\
\hline Available $\mathrm{P}\left(\mathrm{Bray}^{\mathrm{II}}\right)\left(\mathrm{mg} \mathrm{kg}^{-1}\right)^{\mathrm{c}}$ & 17.5 \\
\hline $\mathrm{P}_{\text {oxalate }}\left(\mathrm{mg} \mathrm{kg}^{-1}\right)^{\mathrm{d}}$ & 207.5 \\
\hline Al ${ }_{\text {oxalate }}\left(\mathrm{g} \mathrm{kg}^{-1}\right)^{\mathrm{d}}$ & 2.70 \\
\hline Fe & 2.58 \\
\hline Sandate $\left(\mathrm{g} \mathrm{kg}^{-1}\right)^{\mathrm{d}}$ & 44.3 \\
\hline Silt $(\%)^{\mathrm{e}}$ & 12.0 \\
\hline Clay $(\%)^{\mathrm{e}}$ & 43.7 \\
\hline Texture & Silty clay \\
\hline
\end{tabular}

a: NC analyzer, Sumigraph NC-220F (SCAS, Japan); b: The proportion of absorbed P after shaking $5 \mathrm{~g}$ of soil with $25 \mathrm{ml}$ of $1000 \mathrm{ppm}$ P solution for 24 hours; c: UV spectrophotometer (UV-1800, Shimadzu); d: Inductively coupled plasma mass spectrometer (ICPE-9000, Shimazu, Japan) after oxalate extraction. e: Sieving and pipetting method

Two different $\mathrm{P}$ treatments (sufficient $\mathrm{P}$ incorporation $\left(\mathrm{P}_{\text {inco }}\right)$ and localized $\mathrm{P}$ application via $\mathrm{P}$-dipping $\left.\left(P_{\text {dip }}\right)\right)$ were factorially combined with three rice genotypes in a randomized complete block design with seven replications. For both treatments, $\mathrm{NH}_{4} \mathrm{NO}_{3}$ and $\mathrm{K}_{2} \mathrm{SO}_{4}$ were mixed with soils and puddled in a bucket at a rate of $220 \mathrm{mg} \mathrm{N}$ box $^{-1}$ and $220 \mathrm{mg} \mathrm{K}_{2} \mathrm{O} \mathrm{box}^{-1}$ to develop uniform and $\mathrm{N}$ - and $\mathrm{K}$-sufficient conditions. For the $\mathrm{P}_{\text {inco, }}$ triple super phosphate (TSP) was added at puddling. Then, the mixed soils were filled into a root box at a rate of $500 \mathrm{mg} \mathrm{P}_{2} \mathrm{O}_{5}$ box ${ }^{-1}$ to develop a uniform and P-sufficient condition. The root box was made of transparent acrylic sheets with a size of $30 \mathrm{~cm}$ height $\times 30 \mathrm{~cm}$ length $\times 3 \mathrm{~cm}$ width. The soil was added to the box to a depth of $28 \mathrm{~cm}$. 
For the $\mathrm{P}_{\text {dip }}$ treatment, a $\mathrm{P}$ solution was placed in a spot nearby the transplanted root zone to apply the exact amount of $\mathrm{P}$ in all boxes. We estimated the amount of P-enriched slurry transferred or attached to seedling roots at transplanting as $90 \mathrm{mg} \mathrm{P}_{2} \mathrm{O}_{5}$ box $^{-1}$ based on our previous study ${ }^{29}$. After the $\mathrm{N}$ - and $\mathrm{K}$ -

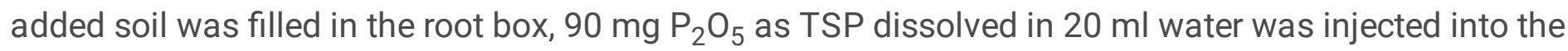
soil at a depth of $3 \mathrm{~cm}$ in the center of the root box. On the same day of these $P$ treatments, one 10-day old seedling was transplanted in the middle of each root box and grown under continuously flooded conditions.

\section{Measurement}

Soil solution samplers (DIK-8393, Daiki Rika Kogyo Co. Ltd., Japan) were installed in one side of the acrylic board in the middle of the $3 \mathrm{~cm}, 7 \mathrm{~cm}$, and $21 \mathrm{~cm}$ depths for four out of seven replicates (Fig. 6). Soil water samples were collected at $3,7,14,21,28$, and 35 DAT. The samples were analyzed for soluble $P$ concentration using a microplate reader spectrophotometer at an absorbance of $630 \mathrm{~nm}$ by following the Malachite Green method $^{30}$.

Three and four replicates were harvested at 21 DAT and 42 DAT, respectively. At each harvest time, shoots were cut at ground level and oven-dried at $70{ }^{\circ} \mathrm{C}$ for $>48 \mathrm{~h}$ to determine shoot biomass. Shoot $\mathrm{P}$ concentration was measured with the molybdate blue method ${ }^{31}$ after dry-ashing at $550{ }^{\circ} \mathrm{C}$ for $2 \mathrm{~h}$ and digestion with $0.5 \mathrm{M} \mathrm{HCl}$. Shoot $\mathrm{P}$ uptake was calculated by multiplying the $\mathrm{P}$ concentration and shoot biomass.

After shoots were removed, root samples were collected using pin-board method as per Kano-Nakata et $\mathrm{al}^{32}$. In brief, roots were pinned with a $5 \mathrm{~mm}$ mesh net and pinboard after which soils were washed off and digital images were taken. The RGA was determined from the digital image as the angle from the soil surface to the shallowest nodal root using ImageJ software (Version 1.52a, NIH, USA). The root system was then divided into 12 compartments or into the center and both sides of the $0-3 \mathrm{~cm}, 3-7 \mathrm{~cm}, 7-14$ $\mathrm{cm}$, and 14-28 cm soil layers to assess spatial root distributions. Root length and surface area of each compartment were measured using Epson Pro-selection X980 Scanner and WinRhizo Pro software (Regent Instruments, Quebec, Canada). Roots were classified as lateral roots $(<0.2 \mathrm{~mm})$ as per Sandhu et al. ${ }^{26}$ and nodal roots ( 0.2 to $2 \mathrm{~mm}$ ) as per Kano-Nakata et al ${ }^{33}$. Roots of $>2 \mathrm{~mm}$ were excluded from the analysis, as they were too large for a single root diameter and most likely occurred as a result of a measurement error. After the morphological analysis, root biomass of each compartment was determined by oven-drying at $70^{\circ} \mathrm{C}$ for $>48 \mathrm{~h}$.

\section{Statistical analysis}

JMP software (v14.0.0, SAS Institute Inc., Japan) was used to perform the statistical analyses. The treatment means were compared at $5 \%$ level of probability using Tukey's HSD test after the single and/or interaction effects of genotypes and $\mathrm{P}$ treatment were confirmed by a generalized linear model. 


\section{Declarations}

\section{Acknowledgements}

We thank to Dr. Takuma Ishizaki, Dr. Hiroki Saito, and technical staff members of the Tropical Agricultural Research Front, Ishigaki Island, Japan, for supporting the experimental soil collection. The authors would like to thank Ms. Mayumi Yonemura, Japan International Research Center for Agricultural Sciences, for conducting soil and plant analysis.

\section{Author contributions}

A.Z.O., and Y.T. designed research and analyzed data; A.Z.O., Y.T., M.M., and T.N. performed research; A.Z.O., and Y.T. wrote the article with contribution of all authors; Y.U. and T.T. developed and provided plant materials; All authors reviewed, revised and approved the articles; Y.T. agrees to serve as the author responsible for contact and ensures communication.

\section{Funding}

Science and Technology Research Partnership for Sustainable Development (SATREPS), Japan Science and Technology Agency (JST)/Japan International Cooperation Agency (JICA) (Grant No. JPMJSA1608); CREST, Japan Science and Technology Agency (JST) (Grant Number JPMJCR1701)

\section{Conflicts of Interest}

The authors have declared that no competing interests exist.

\section{References}

1. Walker, T. W. \& Syers, J. K. The fate of phosphorus during pedogenesis. Geoderma. 15(1), 1-19 (1976).

2. Vance, C. P., Uhde-Stone, C. \& Allan, D. L. Phosphorus acquisition and use: critical adaptations by plants for securing a nonrenewable resource. New Phytol. 157 423-447 (2003).

3. Carpenter, S. R. \& Bennett, E. M. Reconsideration of the planetary boundary for phosphorus. Environ Res. Lett. 6(1). doi:10.1088/1748-9326/6/1/014009 (2011).

4. Nedelciu, C. E., Ragnarsdottir, K. V., Schlyter, P. \& Stjernquist, I. Global phosphorus supply chain dynamics: Assessing regional impact to 2050. Glob. Food Sec. 26:100426 (2020).

5. Tsujimoto, Y., Rakotoson, T., Tanaka, A. \& Saito, K. Challenges and opportunities for improving N use efficiency for rice production in sub-Saharan Africa. Plant Prod. Sci. 22(4), 413-427 (2019).

6. Lynch, J. P. \& Ho, M. D. Rhizoeconomics: Carbon costs of phosphorus acquisition. Plant Soil. 269(12), 45-56 (2005).

7. Nestler, J., Keyes, S.D. \& Wissuwa, M. Root hair formation in rice (Oryza sativa L.) differs between root types and is altered in artificial growth conditions. J. Exp. Bot. 67(12), 3699-3708 (2016). 
8. Lynch, J. P. Root phenotypes for improved nutrient capture: an underexploited opportunity for global agriculture. New Phytol. 223(2), 548-564 (2019).

9. Lynch, J. P. \& Brown, K.M. Topsoil foraging - an architectural adaptation of plants to low phosphorus availability. Plant Soil. 237, 225-237 (2001).

10. Miller, C. R., Ochoa, I., Nielsen, K.L., Beck, D. \& Lynch, J.P. Genetic variation for adventitious rooting in response to low phosphorus availability: potential utility for phosphorus acquisition from stratified soils. Funct. Plant Biol. 30(9), 973-985 (2003).

11. Jia, X., Liu, P. \& Lynch, J. P. Greater lateral root branching density in maize improves phosphorus acquisition from low phosphorus soil. J. Exp. Bot. 69(20), 4961-4970 (2018).

12. Burridge, J. D. et al. A case study on the efficacy of root phenotypic selection for edaphic stress tolerance in low-input agriculture: Common bean breeding in Mozambique. Field Crops Res. 244, 107612 (2019).

13. Vandamme, E. et al. Phosphorus micro-dosing as an entry point to sustainable intensification of rice systems in sub-Saharan Africa. Field Crop Res. 222, 39-49 (2018).

14. Rakotoarisoa, N. M., Tsujimoto, Y. \& Oo, A. Z. Dipping rice roots in P-enriched slurry at transplanting significantly affects grain yield and phenology development in severely P-deficient fields in Madagascar's central highlands. Field Crop Res. 254, 107806 (2020).

15. Oo, A. Z., Tsujimoto, Y., Rakotoarisoa, N.M., Kawamura, K. \& Nishigaki, T. P-dipping of rice seedlings increases applied P use efficiency in high P-fixing soils. Sci. Rep. 10: 11919 (2020).

16. Uga, Y. et al. Control of RGA by DEEPER ROOTING 1 increases rice yield under drought conditions. Nat. Genet. 45, 1097-1102 (2013).

17. Kitomi, Y. et al. Root angle modifications by the DR01 homolog improve rice yields in saline paddy fields. PNAS. 117(35), 21242-21250 (2020).

18. Turner, F. T. \& Gilliam, J. W. Increased P diffusion as an explanation of increased $P$ availability in flooded rice soils. Plant Soil. 45, 365-377 (1976).

19. Akahane, I., Nanzyo, M., Takahashi, T., Sekiguchi, O. \& Saigusa, M. Spatial distribution of phosphorus in the Ap horizon soils of paddy rice fields after rice harvest—Effect of machinery localized fertilizer application at transplanting of rice seedlings-. Jpn. J. Soil Sci. Plant Nutr. 77, 171-177 (2006) (Only Abstract is available in English)

20. Zhu, J., Kaeppler, S.M. \& Lynch, J. P. Topsoil foraging and phosphorus acquisition efficiency in maize (Zea mays). Funct. Plant Biol. 32, 749-762 (2005).

21. Miguel, M. A., Postma, J. A. \& Lynch, J. P. Phene synergism between root hair length and basal root growth angle for phosphorus acquisition. Plant Physiol. 167(4), 1430-1439 (2015).

22. Sun, B., Gao, Y. \& Lynch, J. P. Large Crown Root Number Improves Topsoil Foraging and Phosphorus Acquisition. Plant Physiol. 177(1), 90-104 (2018).

23. Mori, A. et al. The role of root size versus root efficiency in phosphorus acquisition of rice. J Exp. Bot. 67, 1179-1189 (2016). 
24. Arai-Sanoh, Y. et al. Deep rooting conferred by DEEPER ROOTING 1 enhances rice yield in paddy fields. Scientific Reports. 4, 5563 (2014).

25. Rangarajan, H., Postma, J. A. \& Lynch, J. P. Co-optimization of axial root phenotypes for nitrogen and phosphorus acquisition in common bean. Ann. Bot. 122 (3), 485-499 (2018).

26 . Sandhu, N. et al. Rice root architectural plasticity traits and genetic regions of adaptability to variable cultivation and stress conditions. Plant Physiol. 171, 2562-2576 (2016).25. Rangarajan, H., Postma, J. A. \& Lynch, J. P. Co-optimization of axial root phenotypes for nitrogen and phosphorus acquisition in common bean. Ann. Bot. 122 (3), 485-499 (2018).

27. Rose, T. J. et al. Enhancing phosphorus and zinc acquisition efficiency in rice: a critical review of root traits and their potential utility in rice breeding. Ann. Bot. 112(2), 331-345 (2013).

28. Uga, Y., Kitomi, Y., Ishikawa, S. \& Yano, M. Genetic improvement for root growth angle to enhance crop production. Breeding Science. 65(2), 111-119 (2015).

29. Oo AZ, Tsujimoto Y, Rakotoarisoa NM (2020) Optimizing the Phosphorus Concentration and Duration of Seedling Dipping in Soil Slurry for Accelerating the Initial Growth of Transplanted Rice. Agronomy 10,240

30. Motomizu, S., Wakimoto, T. \& Toei, K. Spectrophotometric determination of phosphate in river waters with molybdate and malachite green. Analyst. 108, 361-367 (1983).

31. Murphy, J. \& Riley, J. P. A modified single solution method for the determination of phosphate in natural waters. Anal. Chem. Acta. 27, 31-36 (1962).

32. Kano-Nakata, M., Suralta, R. R., Niones, J. M. \& Yamauchi, A. Root sampling by using a root boxpinboard method. In Methodologies for root drought studies in rice (Shashidhar, H.E., Henry, A. \& Hardy, B. eds.) pp. 3-8, IRRI, Los Baños (2012).

33. Kano-Nakata M., Nakamura, T., Mitsuya, S., Yamauchi, A. Plasticity in root system architecture of rice genotypes exhibited under different soil water distributions in soil profile. Plant Prod Sci. 22(4), 501509 (2019)

\section{Figures}



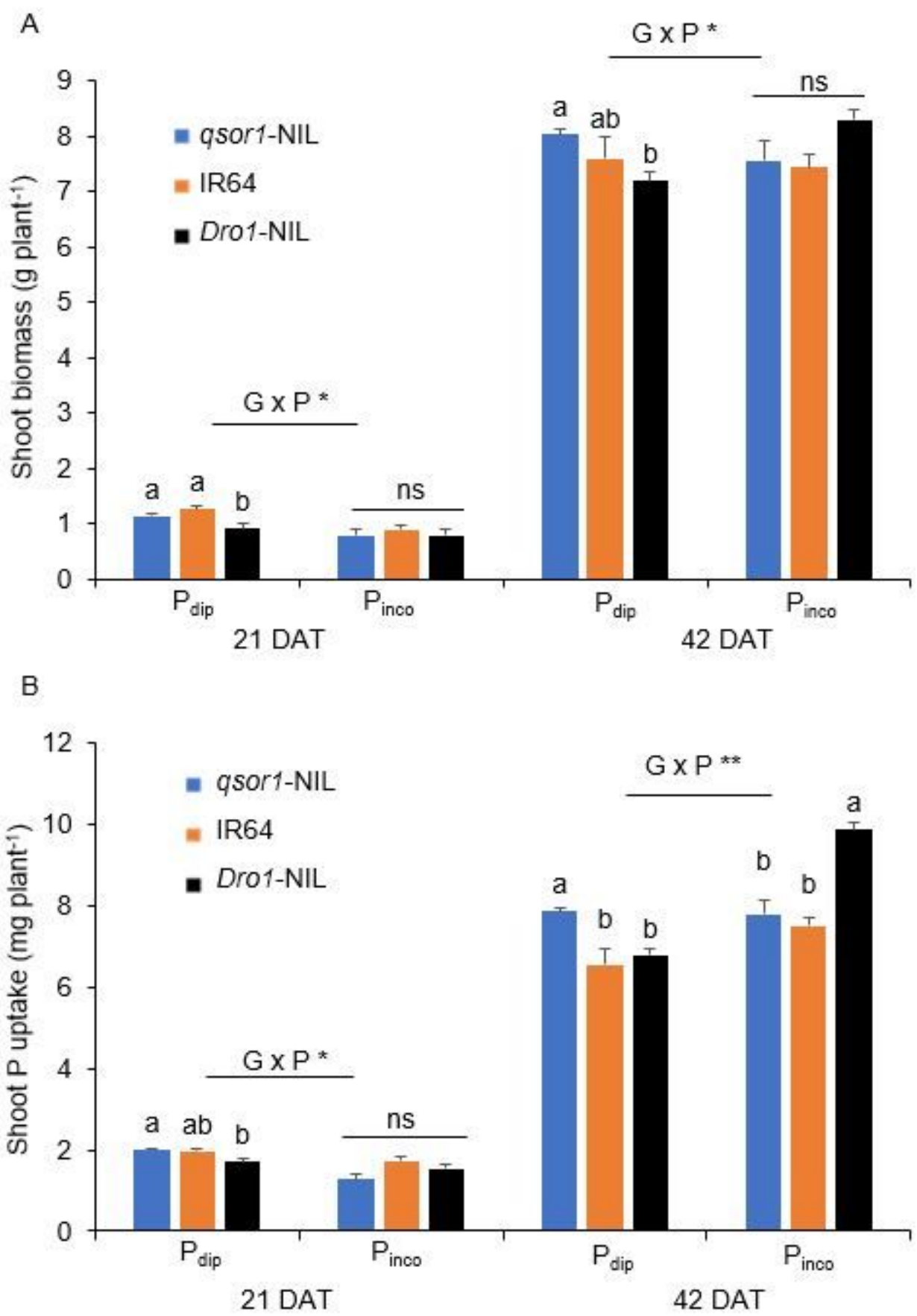

Figure 1

Shoot biomass (A) and shoot $P$ uptake (B) of rice genotypes as affected by different $P$ application methods (P incorporation (Pinco) of $500 \mathrm{mg} \mathrm{P205}$ box-1 vs. P-dipping (Pdip) of $90 \mathrm{mg}$ P205 box-1) at 21 days after transplanting (DAT) and 42 DAT. Different letters and ns within each treatment indicate significant and non-significant differences, respectively, among genotypes at $5 \%$ using Tukey's HSD test. Error bars represent the standard error of replications. The * and ** indicate that the interaction between genotype $(G)$ and $P$ application method $(P)$ are significant at $P<5 \%$ and $P<1 \%$, respectively. 


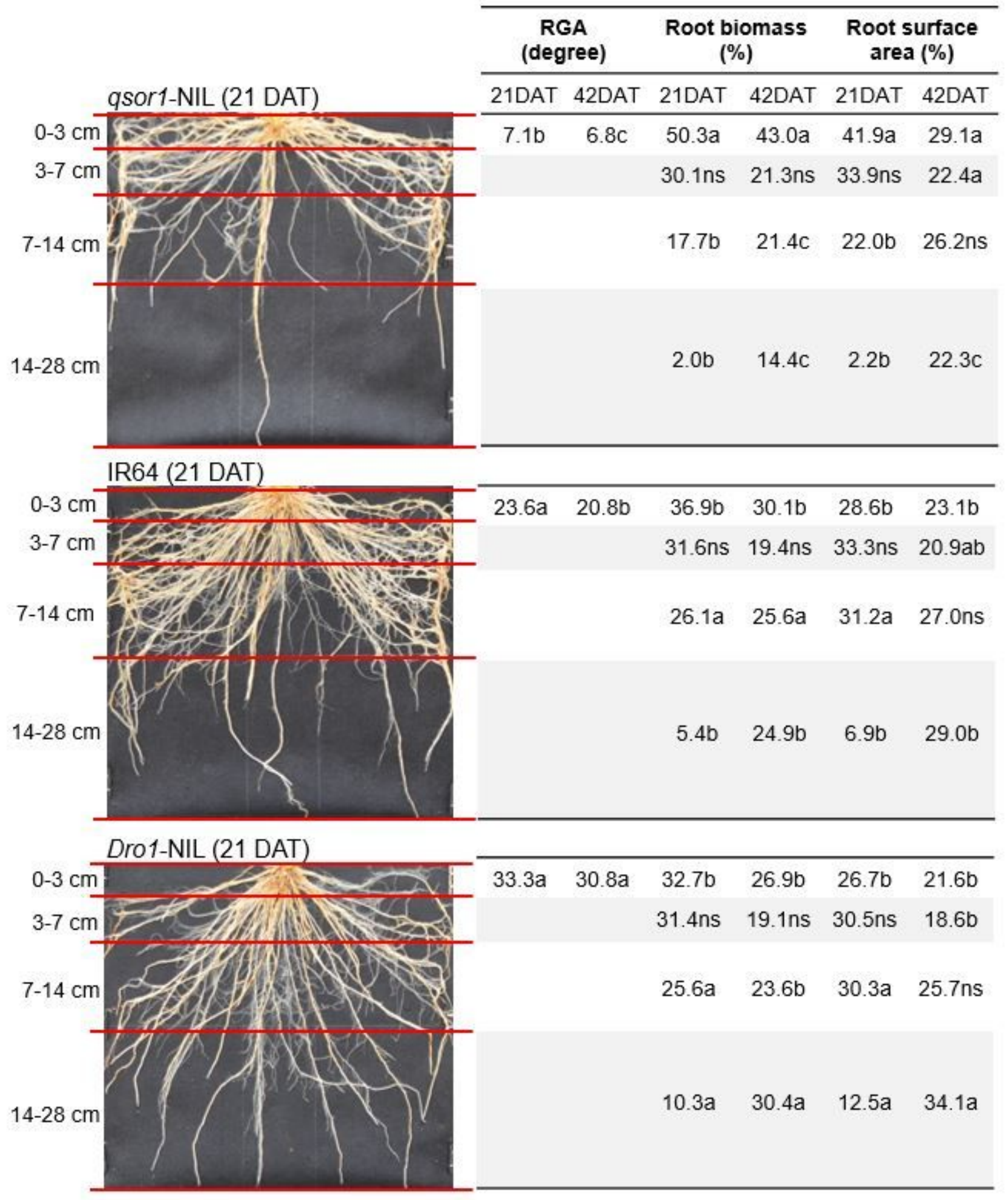

\section{Figure 2}

Root growth angle (RGA) and proportions of root biomass and root surface area in different soil layers of qsor1-NIL, IR64, and Dro1-NIL at 21 days after transplanting (DAT) and 42 DAT under the Pdip treatment. Different letters in the same soil layer indicate significant differences among genotypes at $5 \%$ of Tukey's HSD test. ns: not significant at $5 \%$ level. 


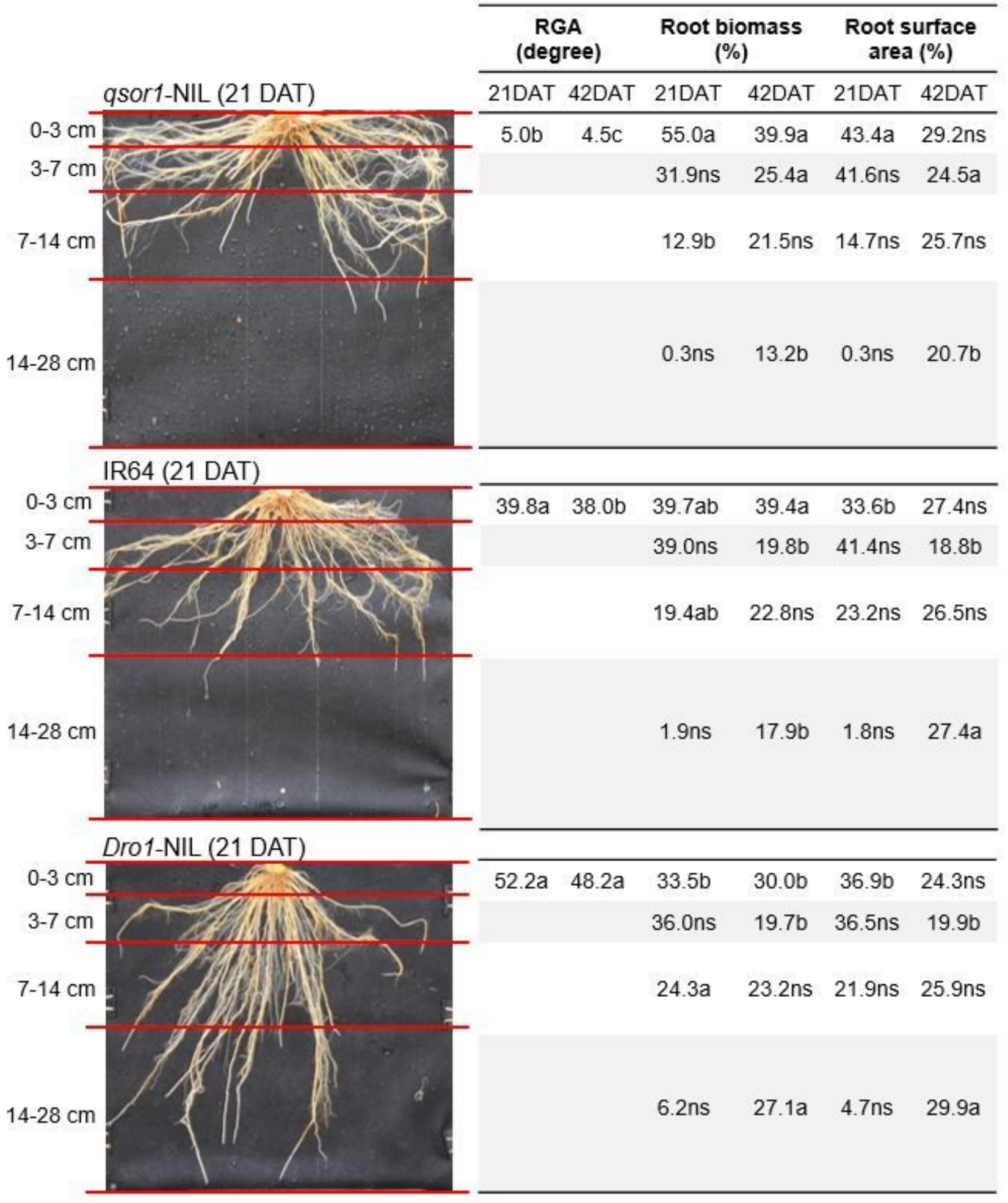

\section{Figure 3}

Root growth angle (RGA) and proportions of root biomass and root surface area in different soil layers of qsor1-NIL, IR64, and Dro1-NIL at 21 days after transplanting (DAT) and 42 DAT under the Pinco treatment. Different letters in the same soil layer indicate significant differences among genotypes at $5 \%$ of Tukey's HSD test. ns: not significant at $5 \%$ level. 

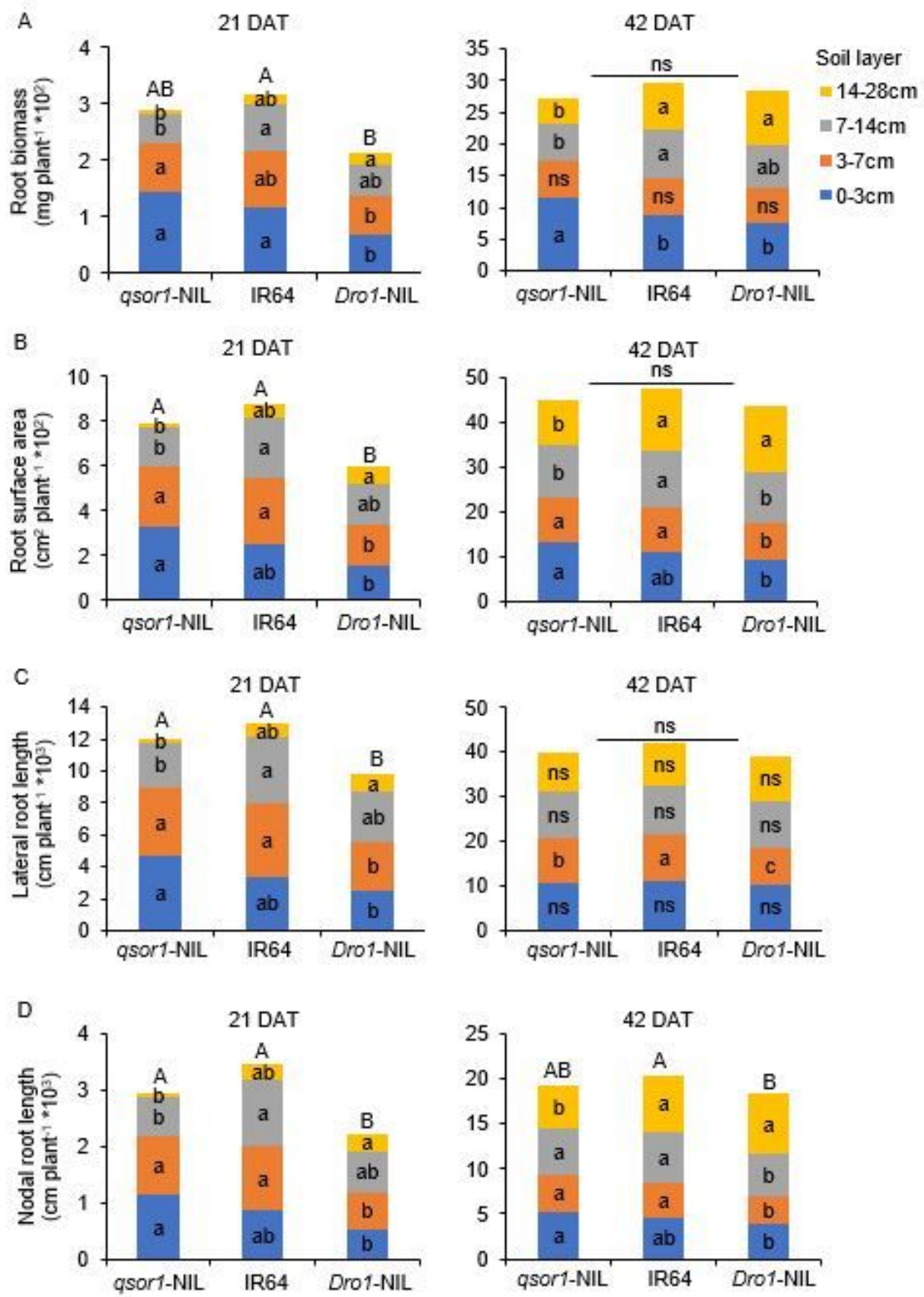

Figure 4

Root development in different soil layers and in total of all layers at 21 days after transplanting (DAT) and 42 DAT under the Pdip treatment. Different small letters and capital letters indicate significant differences among genotypes in these parameters within each soil layer and in total of all layers, respectively, at $5 \%$ of Tukey's HSD test. ns: not significant at $5 \%$ level. 


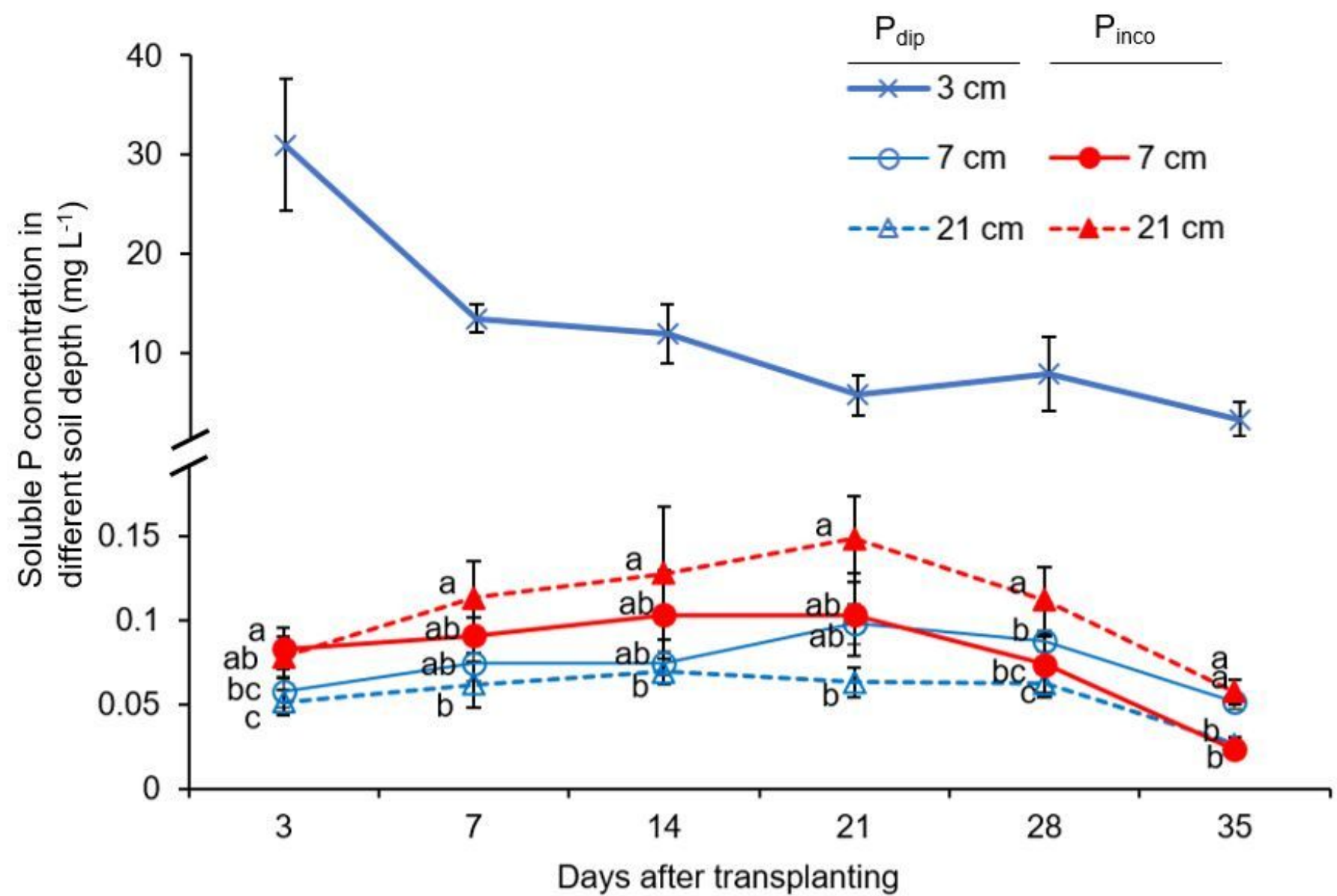

\section{Figure 5}

Spatio-temporal variations in soluble $\mathrm{P}$ concentration as affected by different $\mathrm{P}$ application methods. The cross symbols indicate the value at the $3 \mathrm{~cm}$ depth of the Pdip treatment. The open and closed circles indicate the value at the $7 \mathrm{~cm}$ depth of the Pdip treatment and Pinco treatment, respectively. The open and closed triangles indicate the value at the $21 \mathrm{~cm}$ depth of the Pdip treatment and Pinco treatment, respectively. Data values are an average of three rice genotypes because no significant genotype difference in soluble $\mathrm{P}$ concentration was observed at each sampling time. Error bars indicate standard error of replications. Different letters indicate significant differences at $5 \%$ using Tukey's HSD test among different soil depths $(7 \mathrm{~cm}$ and $21 \mathrm{~cm})$ by $\mathrm{P}$ application methods. The observation at $3 \mathrm{~cm}$ depth was only conducted in the Pdip treatment. 


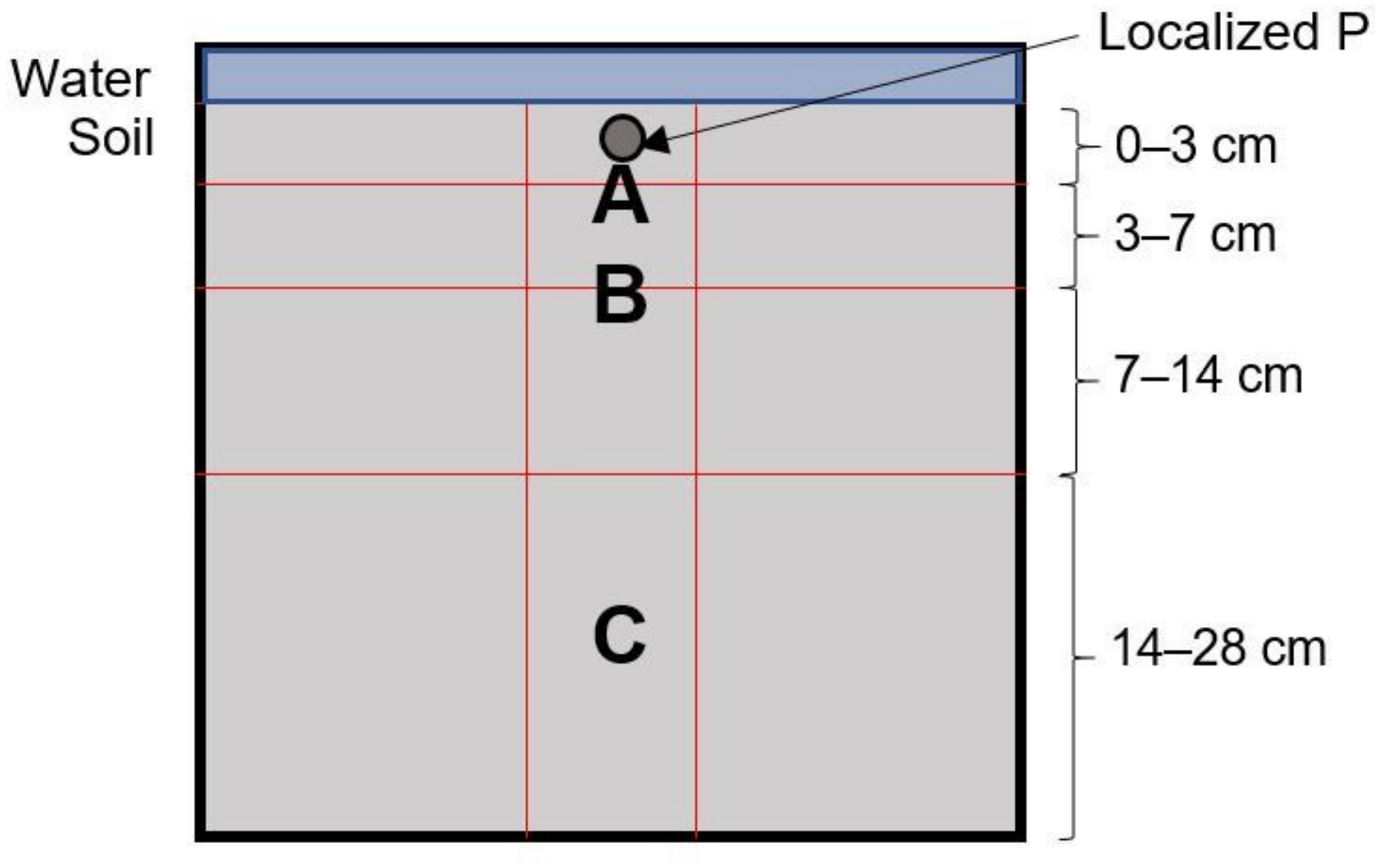

Figure 6

Schematic representation of root box $(30 \mathrm{~cm} \times 30 \mathrm{~cm} \times 3 \mathrm{~cm})$ with the sampling points of soil water solution. Ceramic rhizon samplers were installed in the middle of the box at (A) $3 \mathrm{~cm}$, (B) $7 \mathrm{~cm}(B)$, and (C) $21 \mathrm{~cm}$ depths. 